\title{
Review on microfluidic studies for EOR application
}

\author{
Sekhar Gogoi ${ }^{1}$ Subrata Borgohain Gogoi ${ }^{1}$ (I)
}

Received: 10 September 2018 / Accepted: 8 January 2019 / Published online: 14 January 2019

(c) The Author(s) 2019

\begin{abstract}
All the time the flow of fluids happens below the surface of the earth. These flow processes can only be imagined, but not be fully visualised on how fluid flow behaviour occurs though the porous medium of the rocks. Hence comes the play of microfluidic micromodels. These are a transparent version of slices ( 2 dimensional) porous structure of rocks such as sandstone duplicated onto materials such as glass, polymers and silicon wafers. Fluids such as crude oil, surfactant and polymer solutions and gases such as carbon dioxide $\left(\mathrm{CO}_{2}\right)$ are injected through special pumps into these transparent micromodels. The flow patterns and behaviours hence developed inside the micromodels are studied and analysed. Micromodels have helped in different branches of science such as medicine, genetics, liquid channelling and enhanced oil recovery (EOR). The concern of this paper is to study the flow behaviour and EOR in micromodels. Micromodels can be made to represent a micro version of a partially saturated rock with crude oil. The various chemical EOR processes such as surfactant flooding, polymer flooding, gas flooding injected into crude oil filled micromodels with water saturation is studied. The advancement of front developed between displacing and displaced fluids, the fingering effect, the presence of high permeability streaks is observed. Also the breakthrough of the flood front is analysed from the various experiments reviewed. This review paper is undertaken so as to help researchers find a consolidated and concise literature of the trends and developments in microfluidics especially in EOR.
\end{abstract}

Keywords EOR $\cdot$ Surfactants $\cdot$ Water flooding $\cdot$ Glass micromodels

$\begin{array}{ll}\text { Abbreviations } \\ \text { 2D } & \text { Two dimensional } \\ \mathrm{CO}_{2} & \text { Carbon dioxide } \\ \text { CTAB } & \begin{array}{l}\text { Cetyltrimethylammonium bromide } \\ \text { CMERI }\end{array} \\ & \begin{array}{l}\text { Central Mechanical Engineering Research } \\ \text { Institute }\end{array} \\ \text { EOR } & \text { Enhanced oil recovery } \\ \text { EHD } & \text { Electro-hydrodynamics } \\ \text { EMHD } & \text { Electro-magneto hydrodynamics } \\ \text { IIT } & \text { Indian Institute of Technology } \\ \text { IPA } & \text { Isopropanol } \\ \text { MATLAB } & \text { Matrix Laboratory } \\ \text { MMP } & \text { Minimum miscibility pressure } \\ \text { MST } & \text { Microsystems technology } \\ \text { NOA81 } & \text { Norland Optical Adhesive } 81\end{array}$

Subrata Borgohain Gogoi

subrata@dibru.ac.in

1 Department of Petroleum Technology, Dibrugarh University, Dibrugarh, Assam, India

\section{Introduction}

Aptly named after its usage, microfluidics is the science and technology of systems that process or manipulate small, $10^{-9}$ to $10^{-18} \mathrm{~L}$, amount of fluids. The fluids are run through channels (Whitesides 2006) with dimensions of tens to hundreds of micrometres. Hence the name microfluidics.

The flow of fluids through such micro network called microchannel of pores is laminar. It has opened a whole new gamut of researches as it equips the researcher in controlling the molecular concentration of fluids in space and time which has not been possible with reservoir scale models such as core samples or rock samples.

Another utility of microchannel is that because of laminar flow, the transportation of liquids is predictable and can be easily observed thanks to the transparent nature of microchips. Microfluidic ecosystem needs to have some basic parts which include inlet for fluids, a pump system to move these fluids through the microchips along with sensors to determine the pressure and flow rates at inlet and outlet of the microchips. The whole environment has to be performed very delicately and in a controlled manner. 


\section{The need and value of microfluidics}

Microfluidics is becoming a significant research area in the Petroleum Industry. It is highly valued mainly because of its sheer small size. It makes way for everything better. Commercially it is better because of reduction in the usage of chemicals as well as power consumption.

The total footprint is just about an area of a medium sized study table compared to the much larger footprint and heavy weighted core flooding apparatus. The flooding experiment are now just reduced to this smaller footprint and results obtained are better and most importantly controllable.

Chronological history of microfluidics

\begin{tabular}{|c|c|c|c|}
\hline S. no. & Authors & Year & $\begin{array}{l}\text { Work descrip- } \\
\text { tion }\end{array}$ \\
\hline 1 & $\begin{array}{l}\text { Chatenever } \\
\text { and Calhoun }\end{array}$ & 1952 & $\begin{array}{l}\text { Oil displace- } \\
\text { ment by water } \\
\text { on a glass } \\
\text { model packed } \\
\text { with graded } \\
\text { sand }\end{array}$ \\
\hline 2 & $\begin{array}{l}\text { Mattax and } \\
\text { Kyte }\end{array}$ & 1962 & $\begin{array}{l}\text { Capillary } \\
\text { micromodel } \\
\text { to study fluid } \\
\text { distribution } \\
\text { under various } \\
\text { wettability } \\
\text { conditions } \\
\text { and to find } \\
\text { effects of } \\
\text { permeability } \\
\text { in water-oil } \\
\text { displacement }\end{array}$ \\
\hline 3 & Childress & 1975 & $\begin{array}{l}\text { Acid etched } \\
\text { micromodels } \\
\text { to study oil } \\
\text { displacement } \\
\text { by an aqueous } \\
\text { surfactant } \\
\text { solution }\end{array}$ \\
\hline 4 & Soo and Radke & 1984/1985/1986 & $\begin{array}{l}\text { Flow mecha- } \\
\text { nism of } \\
\text { dilute stable } \\
\text { emulsions in } \\
\text { porous media }\end{array}$ \\
\hline 5 & Danesh et al. & 1987 & $\begin{array}{l}\text { Visualisation of } \\
\text { solution gas } \\
\text { drive and gas } \\
\text { injection in } \\
\text { acid etched } \\
\text { micromodels }\end{array}$ \\
\hline 6 & $\begin{array}{l}\text { Bryant and } \\
\text { Douglas }\end{array}$ & 1988 & $\begin{array}{l}\text { Microbial EOR } \\
\text { on micromod- } \\
\text { els }\end{array}$ \\
\hline
\end{tabular}

\begin{tabular}{|c|c|c|c|}
\hline S. no. & Authors & Year & $\begin{array}{l}\text { Work descrip- } \\
\text { tion }\end{array}$ \\
\hline 7 & $\begin{array}{l}\text { Manlowe and } \\
\text { Radke }\end{array}$ & 1990 & $\begin{array}{l}\text { Foam flooding } \\
\text { in micromod- } \\
\text { els }\end{array}$ \\
\hline 8 & Tong et al. & 1998 & $\begin{array}{l}\text { Surfactant/ } \\
\text { alkali/polymer } \\
\text { flooding on } \\
\text { micromodels }\end{array}$ \\
\hline 9 & Blunt & 2001 & $\begin{array}{l}\text { Flow in porous } \\
\text { media-pore } \\
\text { network } \\
\text { models and } \\
\text { multiphase } \\
\text { flow }\end{array}$ \\
\hline 10 & Zelinger et al. & 2003 & $\begin{array}{l}\text { Formation } \\
\text { damage by } \\
\text { drilling and } \\
\text { production } \\
\text { fluids in glass } \\
\text { micromodels }\end{array}$ \\
\hline 11 & $\begin{array}{l}\text { Rangel- } \\
\text { German and } \\
\text { Kovscek }\end{array}$ & 2006 & $\begin{array}{l}\text { Silicon models } \\
\text { used for study- } \\
\text { ing multiphase } \\
\text { flow in natu- } \\
\text { rally fractured } \\
\text { porous media }\end{array}$ \\
\hline 12 & $\begin{array}{c}\text { Romera and } \\
\text { Kantzas }\end{array}$ & 2007 & $\begin{array}{l}\text { Wettability and } \\
\text { pore geom- } \\
\text { etry effects on } \\
\text { foamed gel } \\
\text { performance } \\
\text { in glass micro- } \\
\text { models }\end{array}$ \\
\hline 13 & Buchgraber & 2008 & $\begin{array}{l}\text { An EOR micro- } \\
\text { model study } \\
\text { with asso- } \\
\text { ciative and } \\
\text { conventional } \\
\text { polymers }\end{array}$ \\
\hline 14 & $\begin{array}{l}\text { Buchgraber } \\
\text { et al. }\end{array}$ & 2011 & $\begin{array}{l}\text { Micromodels } \\
\text { undergoing } \\
\text { viscous fluid } \\
\text { displacement } \\
\text { by polymer } \\
\text { solutions in } \\
\text { glass micro- } \\
\text { models }\end{array}$ \\
\hline 15 & $\begin{array}{l}\text { Emami Mey- } \\
\text { bodi et al. }\end{array}$ & 2011 & $\begin{array}{l}\text { Displacement } \\
\text { behaviours of } \\
\text { polymer solu- } \\
\text { tion in water } \\
\text { wet and oil } \\
\text { wet media }\end{array}$ \\
\hline 16 & Wu et al. & 2012 & $\begin{array}{c}\text { Water flooding } \\
\text { experiments }\end{array}$ \\
\hline
\end{tabular}




\begin{tabular}{|c|c|c|c|c|c|c|c|}
\hline S. no. & Authors & Year & $\begin{array}{l}\text { Work descrip- } \\
\text { tion }\end{array}$ & S. no. & Authors & Year & $\begin{array}{l}\text { Work descrip- } \\
\text { tion }\end{array}$ \\
\hline \multirow[t]{2}{*}{17} & \multirow[t]{2}{*}{ Clemens et al. } & \multirow[t]{2}{*}{2012} & \multirow{2}{*}{$\begin{array}{l}\text { Viscous oil dis- } \\
\text { placement by } \\
\text { polymers and } \\
\text { comparison to } \\
\text { computational } \\
\text { fluid dynamics } \\
\text { simulation of } \\
\text { displacement } \\
\text { process }\end{array}$} & $\overline{26}$ & $\begin{array}{l}\text { Molla and } \\
\text { Mostowfi }\end{array}$ & 2014 & $\begin{array}{l}\text { PVT measure- } \\
\text { ments for } \\
\text { saturation } \\
\text { pressure and } \\
\text { phase volumes } \\
\text { in glass micro- } \\
\text { models }\end{array}$ \\
\hline & & & & 27 & Nguyen et al. & 2014 & $\begin{array}{l}\text { Nanoparticle } \\
\text { stabilised } \mathrm{CO}_{2}\end{array}$ \\
\hline \multirow[t]{2}{*}{18} & \multirow[t]{2}{*}{ Kovscek et al. } & \multirow[t]{2}{*}{2012} & \multirow{2}{*}{$\begin{array}{l}\text { Creation of a } \\
\text { dual porosity } \\
\text { micromodel } \\
\text { for pore level } \\
\text { visualisation } \\
\text { of multiphase } \\
\text { flow }\end{array}$} & & & & $\begin{array}{l}\text { in water foam } \\
\text { for mobility } \\
\text { control in } \\
\text { glass micro- } \\
\text { models }\end{array}$ \\
\hline & & & & 28 & Wu et al. & 2014 & $\begin{array}{l}\text { Study of optic } \\
\text { imaging of }\end{array}$ \\
\hline \multirow[t]{2}{*}{19} & \multirow[t]{2}{*}{$\begin{array}{l}\text { Karadimitriou } \\
\text { and Hassani- } \\
\text { zadeh }\end{array}$} & \multirow[t]{2}{*}{2012} & \multirow{2}{*}{$\begin{array}{l}\text { A review of } \\
\text { micromodels } \\
\text { and their use } \\
\text { in two phase } \\
\text { flow studies }\end{array}$} & & & & $\begin{array}{l}\text { two phase } \\
\text { flow behaviour } \\
\text { in nanoscale }\end{array}$ \\
\hline & & & & 29 & Wang et al. & 2014 & $\begin{array}{l}\text { Impact of } \\
\text { nanopore }\end{array}$ \\
\hline \multirow[t]{2}{*}{20} & \multirow[t]{2}{*}{ Folles $\emptyset$} & \multirow[t]{2}{*}{2012} & \multirow{2}{*}{$\begin{array}{l}\text { Fluid displace- } \\
\text { ments during } \\
\text { multiphase } \\
\text { flow visualised } \\
\text { at pore scale } \\
\text { using micro- } \\
\text { models }\end{array}$} & & & & $\begin{array}{l}\text { confinement } \\
\text { on petroleum } \\
\text { condensation } \\
\text { in micromod- } \\
\text { els }\end{array}$ \\
\hline & & & & 30 & Xu et al. & 2014 & $\begin{array}{l}\text { Effect of geom- } \\
\text { etry and IFT }\end{array}$ \\
\hline \multirow[t]{2}{*}{21} & \multirow[t]{2}{*}{ Rothstein et al. } & \multirow[t]{2}{*}{2013} & \multirow{2}{*}{$\begin{array}{l}\text { Effect of fluid } \\
\text { rheology } \\
\text { on EOR in } \\
\text { microfluidic } \\
\text { sandstone } \\
\text { device }\end{array}$} & & & & $\begin{array}{l}\text { on multiphase } \\
\text { displacement }\end{array}$ \\
\hline & & & & 31 & Conn & 2014 & $\begin{array}{l}\text { The charac- } \\
\text { terization and } \\
\text { visualisation } \\
\text { of multi-phase }\end{array}$ \\
\hline \multirow[t]{2}{*}{22} & \multirow[t]{2}{*}{$\begin{array}{l}\text { Tsakirogou } \\
\text { et al. }\end{array}$} & \multirow[t]{2}{*}{2013} & \multirow{2}{*}{$\begin{array}{l}\text { Use of micro- } \\
\text { models to } \\
\text { study mul- } \\
\text { tiphase flow in } \\
\text { porous media }\end{array}$} & & & & $\begin{array}{l}\text { systems using } \\
\text { Microfluidic } \\
\text { devices }\end{array}$ \\
\hline & & & & 32 & $\begin{array}{l}\text { Al-Dhahli } \\
\text { et al. }\end{array}$ & 2014 & $\begin{array}{l}\text { Pore scale three- } \\
\text { phase flow }\end{array}$ \\
\hline \multirow[t]{3}{*}{23} & \multirow[t]{3}{*}{ Nilsson et al. } & \multirow[t]{3}{*}{2013} & \multirow{3}{*}{$\begin{array}{l}\text { Effect of fluid } \\
\text { rheology on } \\
\text { enhanced oil } \\
\text { recovery in a } \\
\text { microfluidic } \\
\text { sandstone } \\
\text { device }\end{array}$} & & & & impact study \\
\hline & & & & 33 & He et al. & 2015 & $\begin{array}{l}\text { Performance of } \\
\text { micromodels } \\
\text { in nano micro- } \\
\text { models }\end{array}$ \\
\hline & & & & 34 & $\begin{array}{c}\text { Shokrlu and } \\
\text { Babadagi }\end{array}$ & 2015 & $\begin{array}{l}\text { Residual oil and } \\
\text { phase distribu- }\end{array}$ \\
\hline \multirow[t]{2}{*}{24} & \multirow[t]{2}{*}{$\begin{array}{l}\text { Schneider } \\
\text { et al. }\end{array}$} & \multirow[t]{2}{*}{2013} & \multirow{2}{*}{$\begin{array}{l}\text { Measurement } \\
\text { of asphaltenes } \\
\text { using optical } \\
\text { spectroscopy } \\
\text { on a microflu- } \\
\text { idic platform }\end{array}$} & & & & $\begin{array}{l}\text { tion in solvent } \\
\text { injections in } \\
\text { glass micro- } \\
\text { models }\end{array}$ \\
\hline & & & & 35 & Howe et al. & 2015 & $\begin{array}{l}\text { Surfactant phase } \\
\text { behaviour in }\end{array}$ \\
\hline 25 & $\begin{array}{l}\text { Quennouz } \\
\text { et al. }\end{array}$ & 2014 & $\begin{array}{l}\text { Microfluidic } \\
\text { study of foam } \\
\text { flow in EOR }\end{array}$ & & & & $\begin{array}{l}\text { PMMA micro- } \\
\text { models }\end{array}$ \\
\hline
\end{tabular}




\begin{tabular}{|c|c|c|c|}
\hline S. no. & Authors & Year & $\begin{array}{l}\text { Work descrip- } \\
\text { tion }\end{array}$ \\
\hline 36 & Syed et al. & 2016 & $\begin{array}{l}\text { Visualisation } \\
\text { of Steam } \\
\text { Assisted Grav- } \\
\text { ity Drainage } \\
\text { (SAGD) in } \\
\text { micromodels }\end{array}$ \\
\hline 37 & Jung et al. & 2016 & $\begin{array}{l}\text { Characterisa- } \\
\text { tion of a } \\
\text { polyacryla- } \\
\text { mide solution } \\
\text { used for } \\
\text { remediation } \\
\text { of petroleum } \\
\text { contaminated } \\
\text { soils }\end{array}$ \\
\hline 38 & Nguyen & 2016 & $\begin{array}{l}\text { Microfluidics } \\
\text { used for EOR } \\
\text { and carbon } \\
\text { storage appli- } \\
\text { cation }\end{array}$ \\
\hline 39 & Kenzhekhanov & 2017 & $\begin{array}{l}\text { Chemical } \\
\text { EOR process } \\
\text { visualisation } \\
\text { using NOA81 } \\
\text { micromodels }\end{array}$ \\
\hline
\end{tabular}

The whole set up is completely portable and safer to conduct trial runs. Due to less use of instrument, it can also be serviced relative easier than the bulky core flooding equipment. It can be run by a single person due to its simple design in a much-reduced time.

Microfluidics can be utilised as a subject of research in EOR to study fluid flow patterns that occur inside pores and permeable zones of the sub surface rocks. Applications of microfluidics extends from genetics to reservoir engineering. It started in early 1950s and has gained popularity gradually in the field of oil and gas industry (O\&G).

EOR micromodel chips help to get real-time flow behaviour by visualising of fluid flow and relevant in-situ phenomena observed during fluid flow in porous chips (Conn 2014). Microscope and camera combination provides a visual cue of the flow path which can be recorded on a computer. The interesting part is that the fluids interactions occur at micro scale.

It involves processing and controlling small liquid volumes which improves performance in a low cost. Micromodels allow to perform many experiments per unit time compared to traditional macroscopic processes.

Displacement mechanisms are mainly imbibition and drainage. They involve a displacing fluid pushing a displaced phase by development of a front. For example, crude oil can be displaced phase (non-wetting) and water be displacing phase (wetting phase) or vice versa. Buchgraber et al. (2012) mentions that in case of micromodels, comes the direct pore level observation of these displacement mechanisms which help in better understanding of two phase flow behaviour and petro-physical properties. Micromodels containing the pore networks, make it possible to study how pore scale events affect flow patterns and displacements efficiency at larger scales (Folles $\varnothing 2012$ ). EOR can benefitted largely from the use of micromodels. Visual studies enable to understand the effect of changing parameters such as injection rate and types of injection fluids.

Turbulence is an important factor which needs controlling in fluid flow experiments. A micromodel has the advantage that, Reynolds number $\left(N_{R e}\right)$ is always on the laminar regime $\left(N_{R e}<2100\right)$ and viscous flow dominates, thus creating a laminar flow.

\section{Upscaling from micro scale to reservoir scale}

Micromodels are best useful; in carrying out experimental study of flow through porous media at the scale of pore level. And this is a benefit as It helps in attaining the smallest and the most relevant scale to understand petroleum recovery.

Application of microscope allows to observe, understand, identify and analyse pore scale events. This in fact helps to make possible the phenomena of pattern of fluid flow as well as process of displacement and its efficiency at the larger scale. The trial to describe macro scale by use of micro scale has been done. Folles $\varnothing$ (2012) in his research states that an approach is by attempting to derive the Darcy's empirical flow equation through the process of averaging the laws of micro scale.

The upscaling to reservoir level is done mainly by the method of averaging. The properties observed and their values obtained through micromodel experiments on the smallest volume possible, that is, representative elementary volume (REV), are then represented for the whole sample of rock and also to the reservoir scale as a whole. This method gives an idea as to how the rock structures will behave at the reservoir scale.

The pore scale is at a magnitude of $10^{-6} \mathrm{~m}$, core sample are at a magnitude of $10^{-1}-10^{1} \mathrm{~m}$ and actual oil and gas reservoirs are at a scale of $10^{3}-10^{5} \mathrm{~m}$, in such situations, a continuum approach can be taken. The microscale properties are averaged to a constant value. However, fluid saturation and phase pressures all over the total volume cannot be assumed to have the same constant values.

The network on a microchip can be very useful in upscaling. At first, pore scale experiments are conducted on the microchips. Then these can be repeated and observed over some section or even the complete pore network of the microchip. The results obtained from the pore network studies is enough to satisfy the scaling requirement needed for REV. 


\section{D, 2D and 3D micromodels}

Microfluidic chips are a door to the world of pore scale phenomenon occurring inside rocks. Micromodels can have simplest designs in terms of $1 \mathrm{D}$ to complex structures of 2D and 3D. During the early usage of this technology, capillary tubes were utilised in the form of crudest 1D flow. Different diameters were employed to study the interaction-miscibility and displacement of fluids with each other (Buchgraber 2008).

Gradually the idea came to use of glass plates sandwiched together with a very narrow space between the two to represent a 2D structure. Later on in the narrow spaces, glass beads were put which would represent the grains and matrix of rocks and the empty spaces between these glass bead would act to give a porosity to the 2D structure. Fluids were allowed to flow through these glass beads. This helped in understanding the effects of porosity and the permeability of the system.

These models just represented a porous system. They did not represent an actual reservoir rock. Later came the technique of photosensitive fluid coated on glass helping in producing complex pore structure. Lithography techniques gave way to develop much better microchips made of glass, silicon wafer as well as polymers such as PDMS.

The 2D patterns made of thin sections can be stacked together in a series to represent a 3D medium for fluid to flow. These create a geometrically constructed series of simple or complex aggregates. As the microchips represent a 2D flow patterns, the use and extrapolation of the observations and results to the complex 3D medium need to be considered with care.

A case of 3D modelling can be seen (Larpudomlert et al. 2014), where residual saturation in mixed-wet porous media was investigated using a pore-level approach. A mixed wettability system was developed using glass and plastic beads packed into a cylindrical shaped core holder. The core holder was placed in the X-ray microCT scanner for imaging purposes. After cycles of oil and water injection, 3D imaging showed the distribution of the fluids as well as structured of trapped fluids. This helped in getting closer to the actual happenings in a real rock such as sandstone.

Wouters et al. (2014), designed a 3D microfluidic chip for liquid chromatography separation. The 3D chip was constructed from different layers of cyclic olefin copolymer. The chip had three chip modules. Each had a different channel layout and were stacked atop one another to represent a 3D structure.

\section{An overview}

Micromodels studies use periodic geometries or scanned images of rock cross-sections, which are replicated on different types of microfluidic models such as that of glass, polydimethylsiloxane (PDMS) and silicon (Kenzhekhanov 2017). EOR utilises the injection of exotic fluids, such as chemicals, heat, gases and microorganism to improve the recovery of crude oil and gas form depleted reservoirs.

The effects that come into play for production from reservoirs are viscous, capillary and gravity forces. They manipulate the relative permeability of the phases present; leading to changes in rate, quantity and type of production from wells. Taking example of water wet reservoirs, viscous forces favour mobilisation of oil but capillary forces tend to keep oil in place whereas displacement due to fluid density difference is controlled by gravity forces.

EOR aims to increases viscous forces and reduce capillary forces. Injected fluids alter the properties of the oleic or aqueous phases of the reservoir that help the oil to flow easily towards the wellbore. The reservoirs having depleted and trapped residual oil are best candidates for application of such methods.

Generally, flow occurs over hundreds of thousands of metres in oil reservoirs. It is controlled by large viscous forces. Core plug (in lengths of centimetres) experiments are conducted to perform laboratory measurement. Such experiments are able to reproduce many of the flow properties found in real reservoirs if the subsurface consists of porous rocks of similar properties (Follesø 2012).

On the other hand, in micromodels, flow is considered at pore scale (micrometre size). Here the flow is controlled largely by capillary forces. Although they decide the large scale flow patterns in reservoirs. Optimisation of oil recovery at the pore scale will increase the ultimate oil recovery. Thus, the displacement processes during multiphase flow on the pore scale can be used to optimise the production of oil reservoirs.

Chemical EOR consists of Polymer, surfactant and alkali flooding. The mechanisms which are applied by these chemicals are as follows (Kenzhekhanov 2017):

I. Surfactants reduce interfacial tension (IFT) helping mobilize trapped oil by capillarity.

II. Polymer increases viscosity of the injected fluid improving mobility ratio.

III. Alkali forms in situ surfactant by reaction with acidic crude oil reducing IFT and also changes the wettability from oil wet to water wet or less water wet to more water wet.

In the study of the adsorption-desorption of surfactant on reservoir rocks for enhanced oil recovery, it was found that for an extended waterflood following a surfactant slug injection, the surfactants desorbed in water phase (Gogoi 2011). Adsorption-desorption related IFT phenomenon were studied by experiments conducted on core samples

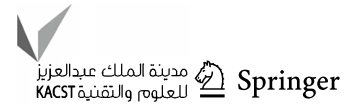


Fig. 1 General schematic of a microfluidic experimental set up

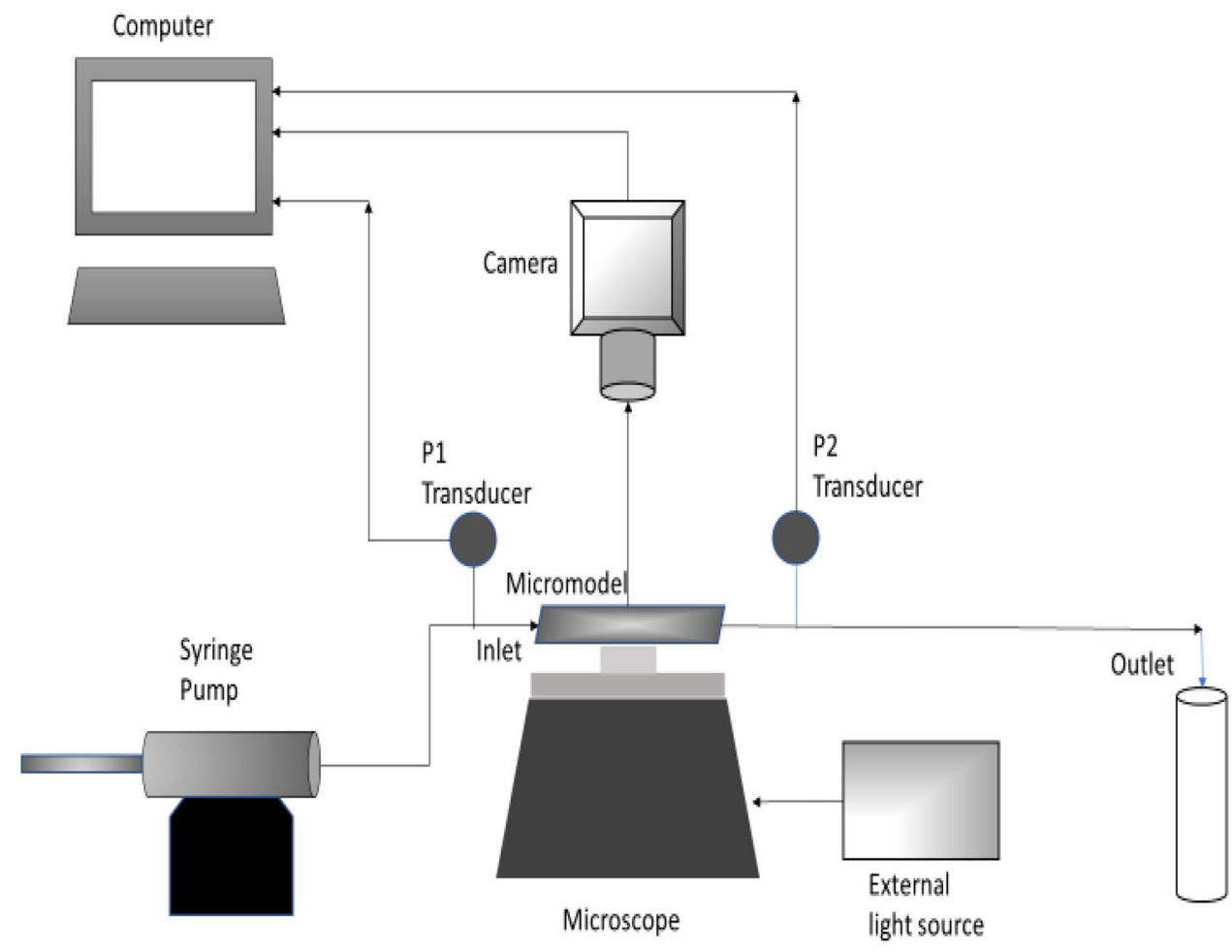

during EOR of medium viscosity oil. Investigation were done to understand the effects on oil-water IFT reduction. This helped in improving the efficiency and economics of the surfactants significantly.

These chemicals when injected into micromodels as in Fig. 1 to drive out oil, can help in understanding the interactions between crude oil and chemicals. Since cores are opaque, non-reusable, expensive and time consuming (Kenzhekhanov 2017), this has led to the development of transparent micromodels to imitate rock samples making them a set of standard tools for visualisation.

It was dealt with $\mathrm{CO}_{2}$ injection in matured and depleted oil reservoirs for the stimulation of oil droplets by utilising the achievement of minimum miscibility pressure (MMP) which lowers oil viscosity for easy flow (Gogoi 2013). $\mathrm{CO}_{2}$ miscible process are either first-contact miscible or multiple-contact miscible. The viscosity of extracted oil got reduced indicating that $\mathrm{CO}_{2}$ displaced oil from pores of the rocks. The GC analysis of extracted oil samples indicated presence of heavy hydrocarbons, as $\mathrm{CO}_{2}$ displaced them through reduction of viscosity and improvement of mobility ration.

The study of the effects of rheological properties for flow behaviour of Assam Crude oil with various chemicals was conducted by Sarmah et al. (2017). Crude oil mixtures were prepared with kerosene blending. For surfactants, anionic black liquor, chrome free lignosulphonate, non-ionic Triton X100 used. Parameters such as shear rate, temperature, density and rpm with kerosene addition on viscous behaviours were investigated. It has been observed that a significant decrease in dynamic viscosity occurs along with an increase in shear stress with increase of shear rate when non-ionic surfactants are added. The high wax content leads to a high pour point making crude oil behave as a non-Newtonian fluid at temperatures below pour point. Surfactants were used as an alternate to dual pipelines using diluents. They helped in emulsifying the heavy crude oil in water and hence be able to transport the low viscosity emulsion in a pipeline. The same idea can be applied in EOR techniques for recovering oil droplets from reservoir rocks.

However, there are limitations (Folles $\varnothing 2012$ ) to the use of microfluidics.

1. There is difficulty in obtaining an exact depth required to be etched on a microchip as per real rock thin slices.

2. A rock structure is heterogeneous. But it takes a great effort to impart that level of heterogeneity to an artificial microchip like on a glass or a silicon model.

3. The pore sizes are not exactly equal. The lager pores in chips in relation to rocks can lead variation in time a liquid can diffuse and flow through.

4. A network of pores is even more difficult to produce which can represent the rock characteristics.

5. 2D models are user friendly but they can never have the same level of continuity as 3D models, which are again complex to make and experiment upon. 


\section{International survey}

\section{Materials and equipment}

The basic requirements are similar for different researchers. The main components can be divided into following categories:

(i) Fluid injection system

(ii) Micromodel holder and micromodel chips

(iii) Optical system

(iv) Cleaning system.

The fluid injection system includes syringe pumps such as Nexus 3000 KR Analytical syringe pump (Folles $\varnothing 2012$ ), Teledyne Isco Model 100 DM (Buchgraber 2008); vessels for gas, brine solution; reservoirs for surfactants, polymers and crude oil. The injection rate varies from units of $\mu \mathrm{L} / \mathrm{min}$ to $\mathrm{mL} / \mathrm{min}$. Tubing, ferrules, connectors form the accessories of this system.

Pressure transducers are utilised to measure pressure differences as well as absolute pressure at a point. The pressure difference is measured between inlet and outlet of the micromodels through connection into tubing in and out of these models (Folles $\varnothing 2012$ ). The systems consist of a pressure transducer, a digital interface box and a display to a computer screen. The pressure is usually measured in bar.

The micromodel is inserted in a micromodel holder. The holder has conduits to which tubes are inserted from pumps to the micromodels chips. The holder can be fabricated from aluminium and consists of two inlets and two outlet ports. The holder ports are aligned with the ports on the micromodel. The ports are sealed with O-rings (Buchgraber 2008; Buchgraber et al. 2012). The holder and chip assembly can be housed in a temperature controlled environment such as putting the assembly on a hot plate.

Instead of a real core, micromodels act as an artificial core (Buchgraber 2008). There are different ways to make micromodel chips. It can be glass chip, PDMS based chips, silicon wafer micromodels, etc. Initial models contained a monolayer of glass beads between two glass plates and done by Chatenever (1952). A plastic sheet was pressurised between beads by Oxall et al. (1952) to avoid bypass of fluids between plates and beads, Tsakiroglou et al. (2013). This model did not require any specific pattern of the porous medium.

Mattax and Kyte (1961) worked on glass micromodels. They used chemical etching of glass plates. Plates were coated with a thin layer of wax and lines were scribed with a stylus. Then the glass was etched in hydrofluoric acid, the model can be made intermediately wet by saturating it with crude oil for several hours. Etching leads to a lenticular pore shape with a typical depth in the range of 50-100 $\mu \mathrm{m}$.
The distance between channels is of the order of $1 \mathrm{~mm}$. The etched plate is covered by a second plate as a cover. Emami Meybodi et al. (2011) used a cover plate, which was drilled with an inlet and outlet holes on either ends to allow fluid to be displaced through the glass micromodel.

PDMS micromodels uses photolithography technique. Nilsson et al. (2013) used to transfer a pattern onto a silicon wafer using a photoresist. The two-dimensional (2D) pattern developed in the photoresist is used as a master, from which multiples can be cast into PDMS. Cross linking polymers can also be used as base. For rocks such as sandstones, a mask was created from cross sectional images of sandstones. It was then used as a template in the microfluidic device that duplicates and helps of approximation of fluid flow through sandstones.

In Silicon wafer micromodels, as very fine structure in the units of $1 \mu \mathrm{m}$ can be prepared using silicon wafers, thus pore size of such micromodels are comparable to the real porous rocks. The silicon is oxidised by etching producing a uniformly wetted surface (Tsakiroglou et al. 2013).

Follesø (2012) used a microscope, an eternal light source, camera and imaging software to comprise the optical system. A normal or an inverted microscope such as Nikon Eclipse TI-FL inverted microscope has been used. The micromodel is placed above the objective lens. Different objectives like $2 \times, 10,20 \times$ are used for zooming. An external light source, such as Nikon Intensilight, is used to deliver light to the microscope. Software such as LabView 2011 National Instruments, Austin, Texas (Schneider et al. 2013), MATLAB Conn (2014), Nikon NIS Elements imaging software (Follesø 2012), GIMP open source imaging software (Conn 2014) can be used.

A micromodel can be reused many number of times compared to a core. The cleaning system is used to clean a fresh micromodel to prepare it for flooding experiments like making it to desirable wettability as well as cleaning it after the experiment is performed. Precipitates due to chemical such as polymers, residual oil can block porous spaces of micromodels clogging it. Hence, a step by step procedure is used. Water is used to push isopropanol (IPA) into the micromodels and holders for removing some residual oil. It is done until there is only immobile oil left in the micromodel. Then toluene is pumped to remove remaining residual oil. Pumping is continued until there is no oil visible or only few immobile patched of oil are left. $\mathrm{CO}_{2}$ is pumped for removing toluene. Finally, vacuum and heat is used to remove and vaporise residual toluene (Buchgraber 2008).

There are procedures to maintain water wet or oil wet condition of micromodels. Toluene, acetone, vacuum, distilled water and hydrochloric acid are utilised to make water wet situation while sodium hydroxide, trichloro-methyl silane (TCMS), dehydrated toluene, methanol are used to 
make oil wet situation, as applied by Emami Meybodi et al. (2011).

\section{Detecting and colouring material and chemicals}

The microscope can be equipped with florescence filters. Each filter let a different wavelength of light. Fluorescence is also used to get a better contrast between different fluids. Fluids and their fluorescent additives are selected properly. Additives such as fluorescein, FT175 are used for distilled water, Nile red is used for Decane or other oil phase. Nile red is soluble in organic solvents and hydrophobic lipids, but insoluble in water, used by Folles $\varnothing$ (2012). Hence, it is a good additive to differentiate between fluids flowing inside micromodels.

\section{Studies on micromodels}

Various authors have done experiments on flow mechanisms, micromodels and EOR techniques on micromodels. Below are some of the research findings.

\section{Mattax and Kyte capillary micromodel (1961)}

Mattax and Kyte (1961) studied the fluid distribution under various wettability conditions, and on the effects of wettability on water-oil displacement. The capillary micromodel was a network of interconnecting capillary grooves etched into a flat glass plate. Water flood behaviour curves of the micromodels were observed in linear flow conditions from which water-oil relative permeability characteristics of the micromodel can be calculated. They stated that since the behaviour of the micromodel was similar to that of the rock, it is probable that the capillary micromodel is a reasonable representation of a natural porous medium.
Observations were done on static fluid distributions, strongly water-wet system, where in water and residual oil distribution, continuous residue oil pockets usually extend over very short distances. Only a little residual oil is in the form of free spherical droplets. In slightly water wet systems, brine saturated model was flushed to connate water by crude oil injection. The fluids were made to be in contact with the models for several hours. It was seen that residual oil pockets were usually larger when micromodel is slightly water wet than in strongly water wet condition. In further experiments it was observed that sweep efficiency in a waterflood under slightly water wet state is due to fingering effect of water.

\section{Soo and Radke on fluid flow mechanisms on emulsion and micromodels (1984-1986)}

Soo and Radke (1986) stated that emulsion droplets are actually trapped when they flow through a porous media. There are two modes of capturing; Straining and Interception as in Fig. 2. If drops clog pore constrictions of sizes smaller than their own by getting trapped in between grains, the mode is termed as straining. On the other hand, if drops get attached to the pore walls due to Van der Waals forces, the trapping is termed as interception.

Soo and Radke conducted in a glass micromodel, a typical glass micromodel with holder is shown in Fig. 3, study based on Ottawa sand where oil-in-water emulsions of drop sizes 1-50 $\mu \mathrm{m}$ was injected. Crude oil-in-water emulsions were injected into water saturated micromodel at $0.02-0.12 \mathrm{~mm} / \mathrm{s}$. The $20 \mu \mathrm{m}$ drops lodge in the pores exhibiting straining capture mechanism. When pressure drop was increased, the drops slipped through the pores to flow downstream. For smaller drops, some were retained on the surface of the sand grains hence interception capture mechanism occurred. Hence, a permeability occurs during emulsion flow in which
Fig. 2 Different capture modes of emulsion in a porous media of grains

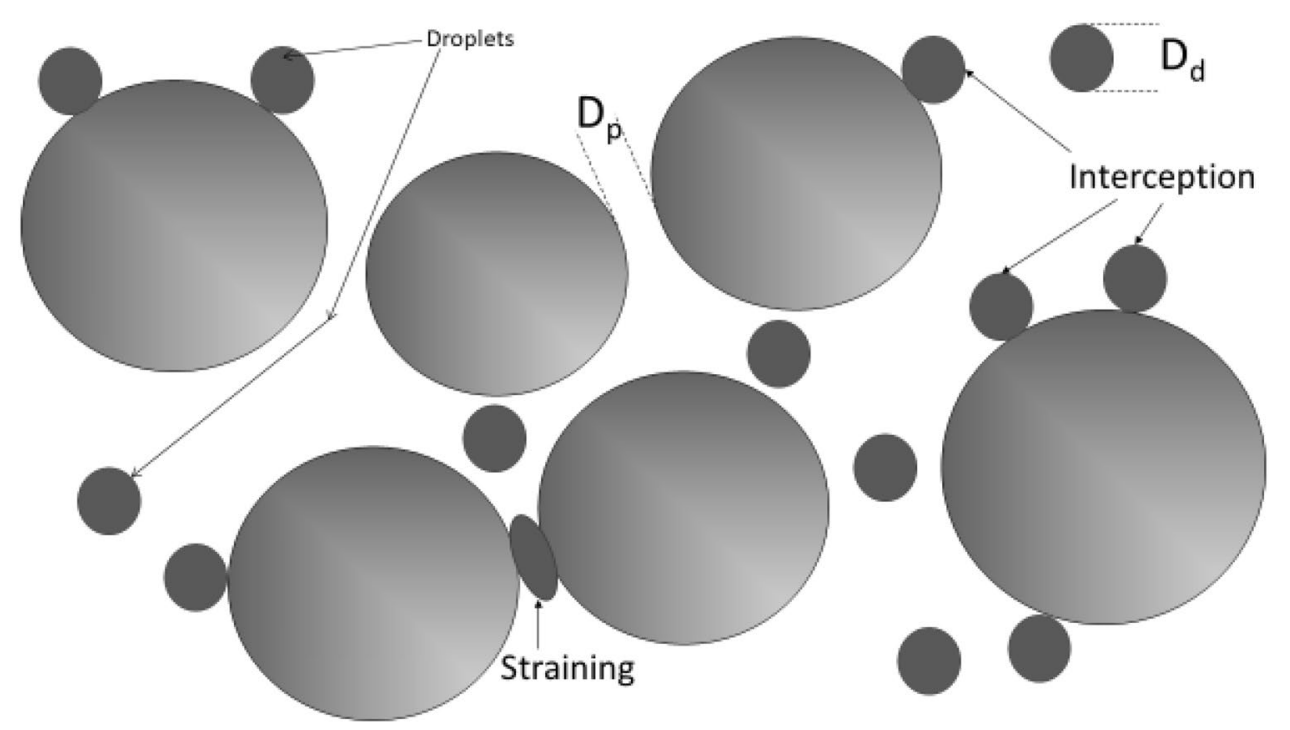




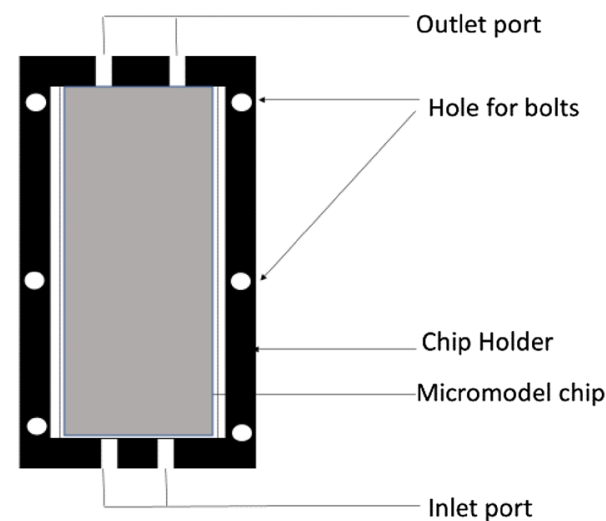

Fig. 3 The glass micromodel and holder used by Soo and Radke for micromodel study

it is mostly due to retention of drops in the pores (Soo and Radke 1984).

\section{Carbon dioxide in EOR by Blunt et al. (1993)}

Blunt et al. (1993) stated the usage of carbon dioxide in enhancing oil recovery. A projection was made that for every kilogram of $\mathrm{CO}_{2}$ injection, an approximate amount of one to one quarter of additional oil was recovered.

Carbon dioxide when flooded with sufficiently high pressure, it forms mixtures with the crude oil, which are miscible in laboratory tests, a $40 \%$ out of the remaining oil can be recovered. $\mathrm{CO}_{2}$ flooding is attractive if the crude oil is light and reservoir is less heterogeneous.

\section{Flow in porous media-pore network models and multiphase flow by Blunt (2001)}

Blunt (2001) in porous media, stated the advantages of pore scale modelling for study of multiphase flow and transport. Pore scale displacement can be observed directly in micromodels. This helps in deeper understanding of imbibition and drainage process. The pore scale models are used investigate variety of phenomena such as wettability, mass transfer, influence of flow rate on residual oil saturations, and three-phase flow in fractures.

Micromodels having rough or angular cross-section, a wetting phase may occupy crevices in the layers. At the same time the non-wetting phase occupies the centre of the pore spaces. Different pore shapes influence distribution of the phases. In circular pores, a single phase is allowed at a time, whereas in angular pores, the centre is occupied by non-wetting phase, with wetting phase occupying only the corners (Fig. 4).

The oil layers can retain connectivity of oil phase even to very low saturations. This is possible because of the ability of the oil in forming a layer sandwiched between water and

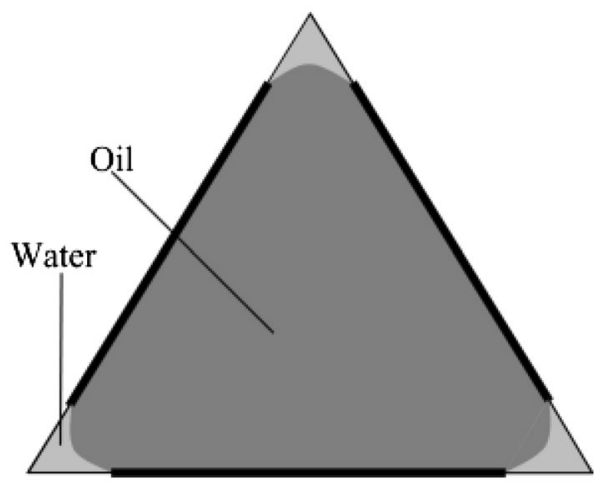

Fig. 4 Oil and water phase in a triangular pore (Courtesy: Martin Blunt)

gas. This in turn during immiscible gravity drainage, helps to gain higher oil recovery.

\section{EOR-micromodels study with polymers by Buchgraber (2008)}

Buchgraber (2008) made a study to understand the immiscible displacement of conventional and associative polymer solutions with dead oil of $450 \mathrm{cP}$ by application of force imbibition. The motive was to observe front stability, breakthrough time and recovery and ultimate recovery with better representation of pore space geometry.

The micromodel used had same homogeneous pore space as Berea sandstone. It was etched on a silicon wafer bonded with glass for building of flow channels. High resolution photographs were taken on micro and meso-scales. It was found that with increase in polymer concentration, recovery, sweep efficiency and front stability were also improved.

Brine flood met with unfavourable mobility ratio creating viscous fingers leading to an early breakthrough, thus a poor sweep efficiency and recovery factor. On the other hand, this was reversed by injection of conventional and associative polymers, which with increased concentration lead to better recovery at the time of breakthrough.

The fingers decreased in quantity and length with increasing polymer concentration. Although a stable displacement was observable only by use of associative polymers. But even after flooding with ten times the pore volume of polymer, there was no change in ultimate recovery citing that polymers cannot recover any more residual oil after ultimate recovery was reached.

\section{Microscopic and macroscopic displacement behaviours by Emami Meybodi et al. (2011)}

Emami Meybodi et al. (2011) in studied microscopic and macroscopic displacement behaviours of polymer solution 
water wet and oil wet media. A glass micromodel was taken under strongly oil wet and water wet conditions. Two waterflood and 20 polymer flood experiments were conducted to investigate wettability effects on microscopic and macroscopic efficiency of polymer oil recovery.

There was observation of thick connate water films on pore walls in the strongly water wet medium. A uniform front developed and resulted in enhanced macroscopic sweep efficiency. Whereas, no thick water film was observed in the strongly oil wet case, but a trapped water phase occurred within the oil phase. The polymer solution hardly completely swept the oil.

Wettability of the medium and apparent viscosity of the polymer solution influenced the pattern of flow and ultimate oil recovery. At breakthrough and at the end of the experiment, the oil recovery was much higher in the water wet medium than in the oil wet medium. For both wettabilities, at lower viscosity ratio the recovery factors were higher.

\section{Study of fracture geometry effect on breakthrough time in micromodels by Kamari et al. (2011)}

Kamari et al. (2011) studied miscible displacement process in depleted reservoir. The tests used n-heptane to displace n-decane in glass micromodels which had different fracture geometries. The investigation was done to see effect of single fracture on breakthrough tie during miscible displacement process.

The plots of breakthrough tie against dimensionless fracture length showed that the more the length of the fracture increased, the breakthrough happened earlier. As for fracture orientation, with its orientation to flow direction was increased, the breakthrough occurred later.

A breakthrough time equation was developed representing the trend of a specified fracture length with different fracture orientations using 40 experiments conducted in various patterns of glass micromodels. For validating, the breakthrough time was calculated using image processing techniques.

\section{Fluid displacement during multiphase flow using micromodels by Follesø (2012)}

The study was conducted by Follesø (2012) on Silicon Micromodels adopted to properties of real porous rocks. Spontaneous water imbibition, primary drainage, $\mathrm{CO}_{2}$ gas injection three phase flow studies were conducted. The flow processes were controlled by adjustment of injection flow rates and injection pressures. Also changes were made in the boundary conditions through closing and opening production ports.

In spontaneous imbibition, at first regimes, stable flow of water was observed. This resulted in good sweep efficiency.
The second regime, where large water supply to the micromodel resulted in capillary fingering causing low sweep efficiency.

In primary drainage, during first regime, a stable front was observed during oil flow giving a good sweep efficiency. However, at second regime, fingering patterns occurred causing early breakthrough and a poor sweep efficiency. At low flow rates, capillary fingering occurred. Bypass of water from merging of both small and large fingers was seen.

In three-phase $\mathrm{CO}_{2}$ injection, $n$-decane spreads in a water $/ n$-decane $/ \mathrm{CO}_{2}$ system. Silicon micromodels are wetted in the order of $\mathrm{CO}_{2}<$ oil $<$ water. This helped in $\mathrm{CO}_{2}$ entering large pores even if it had to pass water-filled in the process. $\mathrm{CO}_{2}$ displaced oil via piston displacement. During $\mathrm{CO}_{2}$ displacement, once it has displaced oil from certain regions reducing the oil saturations, the $\mathrm{CO}_{2}$ migrates to remaining oil filed pores and displacement of new oil pores begins. This results in a better and efficient oil production.

\section{Review of two phase flow in micromodels by Karadimitriou and Hassanizadeh (2012)}

In consolidated glass-bead micromodels, capillary pressure controlled the wetting film imbibition ahead of the main displacement front for a liquid-gas system. Another micromodel study revealed the transition from capillary to viscous flow during drainage. It was found that, at a lower capillary number, invading liquid flowed through one single channel at a time. As the capillary number became large, the viscous forces took prominence.

Micromodels helped in measurement of the area of interfaces formed between phases. The image processing has gained popularity is measuring phase saturation and interfacial area. Relative permeability and saturations of non-wetting phase was calculated by collection of differential pressure across the micromodel using a pressure transducer.

In EOR processes, Karadimitriou and Hassanizadeh studied work of Dong et al. (2007) for displacement mechanism of alkaline flooding in Enhanced Heavy oil recovery. The Fig. 23 of the paper by Karadimitriou and Hassanizadeh (2012) indicates the following, the left images show micromodel and right shows pore level image. Upper left micromodel has heavy oil with connate water at the end of oil injection. The upper right image shows that the solids are surrounded by water film, hence water wet, with oil acting as continuous phase.

Once alkaline slug injection is commenced in lower images, it penetrated into residual oil phase creating discontinuous water ganglia inside oil channels to form water in oil emulsion. Oil was displaced in the form of water in oil emulsion. Along with this, the change in wettability helped in water flow blockage. 


\section{Effect of fluid rheology on EOR in a PDMS micromodel by Nilsson et al. (2013)}

Nilsson et al. (2013) studied effect of fluid rheology on a microfluidic platform. The micromodels were designed to reproduce a two dimensional slice from a sandstone core. PDMS was used in the fabrication of micromodel utilising photolithography techniques.

Several fluid and solution were experimented with to compare oil recovery. Water, cetyl-trimethylammonium bromide (CTAB) solution, shear thinning Flopaam solution, shear thickening fluid containing polyethylene oxide (PEO) and fumed silica nanoparticles were used. The tests were performed at increasing flowrates. The oil recovery increase as the solution used changed from water till the shear thickening fluid.

The second part of the experiment was observation of recovery of oil as a function of capillary number. The data set were found to collapse to a single master curve. The oil recovery increased in similar values for different solution with an increase in capillary number. The difference among solutions was minimal compared with that of changing flowrates.

\section{Multiphase flow in micromodels by Tsakiroglou et al. (2013)}

Tsakiroglou et al. (2013) studied displacement mechanisms in micromodels. In drainage it showed there occurred invasion percolation. First neck of pore is invaded due to pressure greater than capillary pressure and then pore body is invaded. Subsequently others pores are gradually invaded. Imbibition has helped identify collapse in pores and in channels.

Viscous fingering occurs in both miscible and immiscible displacements. This happens when mobility ratio $(M)$ is much greater than one. The micromodel used was a resin micromodel. The fingering appeared at around $M$ valued to ten.

According to University of Waterloo, in micromodels, high recovery occurred in gas tertiary recovery caused the gas injected reconnected the oil phase and created an oil bank ahead of the gas front. Hence micromodels have shown that physical mechanisms are governed by pore scale properties.

\section{Asphaltenes measurement using optical spectroscopy on a microfluidic platform by Schneider et al. (2013)}

Schneider et al. (2013) used glass micromodels to measure the asphaltenes content in crude oil samples. They used optical adsorption technique. Micromodels helped reduce the measurement time of asphaltenes content from several days to only several minutes. This in turn helped in quick processing time in oil fields.

The best utilisation is that it helps to analyse oil samples multiple times on the same micromodel. The measurement repeatability of microfluidic apparatus offers quality monitoring. As micromodels are in micron sized pores, thus sample and solvent volume requirements are much smaller than conventional methods. Hence there is proper utilisation of precious crude oil samples.

Pore scale three-phase flow impact study by Al-Dhahli et al. (2014)

Al-Dhahli et al. (2014) laid emphasis of three phase flow's importance in EOR processes. The used a three-phase flow pore-network model, to study the microscopic displacement processes. Calculations were done for relative permeability and capillary pressure functions for a range of wettabilities.

Simulations were performed which showed that after water flooding, at pore scale, there was a higher residual oil saturation for a water wet system in comparison to residual oil saturations after gas injection. This was attributed to the presence of stable oil wetting films that provided hydraulic connectivity at low oil saturations.

In addition, functions generated from pore scale were used in reservoir scale model. A demonstration was done on the impact that the three phase flow function has on the sweep efficiency after gas injection.

\section{Characterization of polyacrylamide (PAM) solution by Jung et al. (2016)}

Photoshoots of micromodels where PAM solution was displaced against air and decane were taken. The still images and videos captured were analysed using Image $\mathbf{J}$ software for computation of biopolymer saturation and PAM-Decane displacement ratios, Jung et al. (2016). It was observed that the flow rate effect is more prominent for decane. It was seen, low flow rates and low concentrations gave low displacement ratios. Although displacement ratio is higher for PAM than that of using deionised water. The higher concentration does not guarantee higher displacement ratios.

\section{Microfluidic study for EOR by Nguyen (2016)}

Nguyen (2016) experimented on nano-stabilise $\mathrm{CO}_{2}$ foam flooding and oil recovery operations, to quantify minimum miscibility pressure (MMP) through a microfluidic approach and contact angles between phases. Figure 5 shows a microfluidic setup used by Nguyen. 


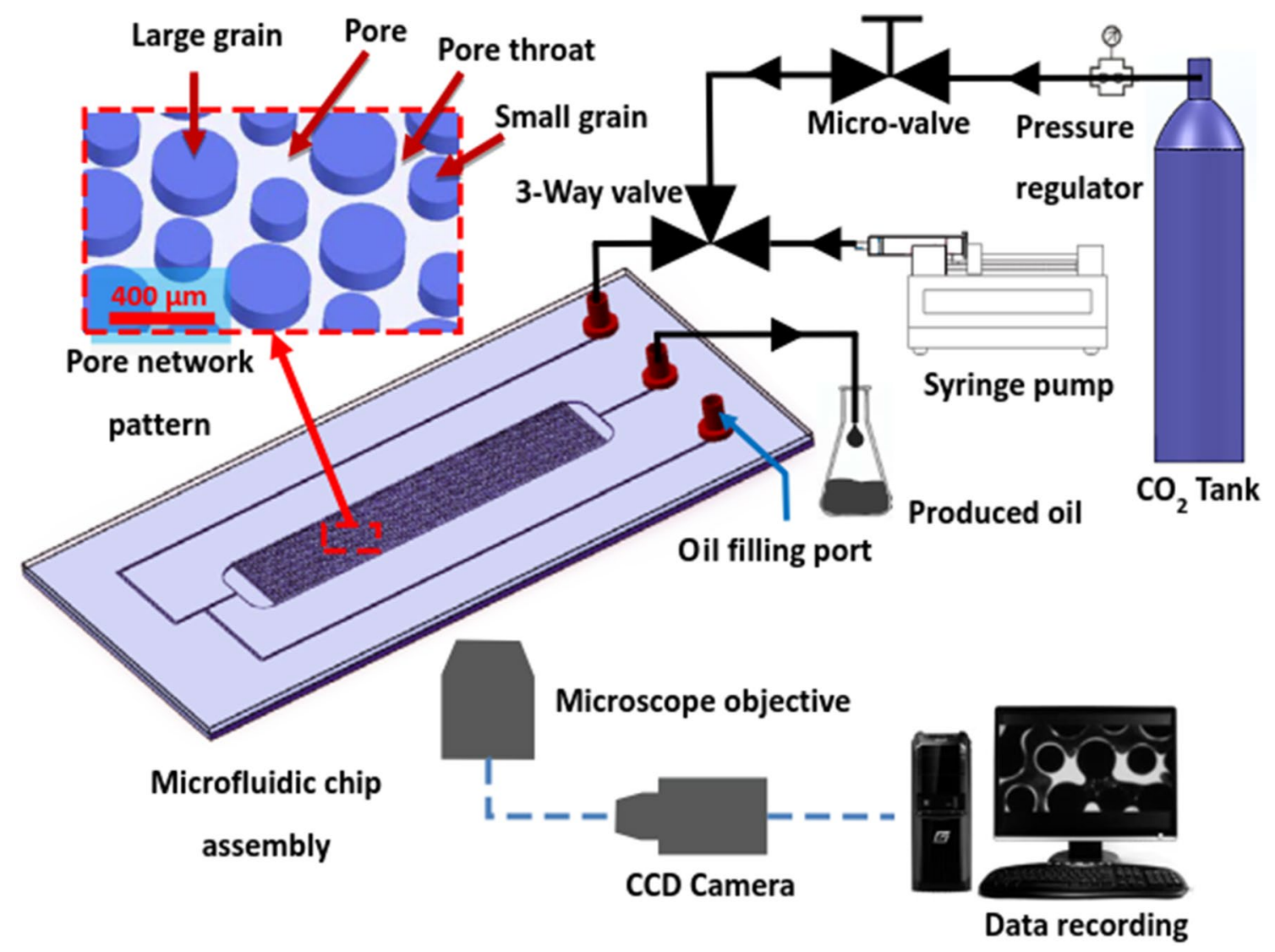

Fig. 5 A microfluidic experimental setup (Courtesy: Nguyen 2016)

It was seen that the nano-particle stabilised $\mathrm{CO}_{2}$ foam flood increased the oil recovery to three-fold compared to just $\mathrm{CO}_{2}$ gas flood. This happens because the nano-particles makes the pore scale bubble structures. Light, medium and heavy oil were used for testing of oil recovery, all of which showed substantial increase in oil recovery.

MMP was another calculation performed in the micromodel. Micromodels helped in better measurement speed plus a fast-quantitative analysis. MMP was obtained within $30 \mathrm{~min}$ in comparison to the weeks taken if slim tube test were to be used. In case of fluorescence, a better contrast was achievable between $\mathrm{CO}_{2}$ and oil which helped in distinguishing better inside micromodels.

Experiment was also carried out to understand phase interactions. The phases were oil, water, nanofluid and rock using microchannels. Contact angle measurement were performed at different injection pressures for different phase combination. The contact angles using nano fluid showed lower values compared to that by water. This shows that nanofluid made better water wettability which in turn is favourable for the recovery of oil.

\section{Chemical EOR visualization by Kenzhekhanov (2017)}

Kenzhekhanov (2017) experimented the effects of temperature, interfacial tension, wettability and fractures on displacement efficiency using NOA81 micromodel. Higher temperature reduced IFT slightly although the mobility ratio remained the same in water flooding process, hence no alteration in recovery.

The water wet micromodels gave higher recovery although no additional recovery too place after breakthrough. But, in spite of oil-wet micromodels had lower recovery at breakthrough, there was significant recovery after breakthrough. In the surfactant flooding, IFT reduction was more effective in oil wet micromodels.

It was seen that half-fractured micromodel produced lesser than homogeneous micromodel. However, the fully fractured micromodel gave no recovery. When surfactant flooding was applied, there was improvement in recovery in both micromodels. But there was need of larger amount of injection of pore volumes for displacement of oil.

Additionally, microemulsion generation, dead-end pore displacement and fluid flow reversals took place in the flooding experiments. 
Pore and grain size effect during polymer flood in micromodels by Lacey et al. (2017)

Lacey et al. (2017) conducted two phase displacement process on micromodels to understand the effect of pore and grain size on the polymer flood efficiency. Investigations were made on oil recovery, displacement dynamics and oil entrapment. The polymer flood was compared to water flood for three types of micromodels having fine, medium and coarse-grained patterns.

Visualization and image analysis was done to study the oil displacement dynamics and distribution of residual oil ganglia using optical microscope. Displacement front stability was investigated both qualitatively and quantitatively. The results showed that xanthan solution produced a more stable displacement than water. This will hence give to a delayed breakthrough of fluid.

However, it was seen that, polymer flooding was less effective for fine grains when compared to medium and coarse grained micromodels. This suggested that many sandstones comprise of finer to medium grain sizes, recovery efficiency of waterflood is better than polymer flood.

\section{National survey}

\section{Self-organized micropatterning of thin viscous bilayers by Bandyopadhyay et al. (2010)}

Bandyopadhyay et al. (2010) studied the action of van der Waals forces in self-organized ordered microstructure formation in thin viscous bilayers through nonlinear simulations. A master made of physic-chemically patterned substrate aligns the instability of a thin viscous bilayer. This helps in direct fabrication of complex 3D imbedded structures like microchannels and micro droplets.

Patterns on films are made either using a topographically or chemically patterned solid substrate for controlling of spatial strength of the intermolecular force. Their studies have shown that it is capable of replicating patterns due to the transferrable nature of the patterns formed at the embedded liquid-liquid interface to the free and stable liquid-air interface.

A dominant role is played by weak van der Waals forces. Gravity forces are insignificant for ultra-thin films. Hence, a reduction in the dimension of the system to sub-micron level, the micro-gravity conditions can be applicable in a laboratory. The details and simulations were of direct interest in designing and interpreting the experiments involving these bilayers on the complex chemically patterned substrates.

\section{Paper-based microfluidic devices for arsenic detection by Nath et al. (2014)}

A paper-based microfluidic device was fabricated by Nath et al. (2014) for detecting very low concentration of Arsenic ions by the use of gold nanosensors. Whitman filter paper was used for the purpose to prepare $\mathrm{Y}$ shaped fluidic channel by micromachining methods using $\mathrm{CO}_{2}$ laser engraving system.

Paper substrate can develop a self-driven fluid flow with a steady flow rate because of the capillary action through fibres and pores. The low flow rate helps in retaining a very low concentration of arsenic in the microchannel for a time period during which it interacts with nanosensors. The interaction leads in development of a visible dark bluish-black precipitate.

UV-Vis technique was used for exploring the affinity of Gold nanosensors towards arsenic ions detecting a colour change. This paper based system is portable, free of power and cost effective. It is a safe procedure for arsenic detection.

\section{Microdevice for plasma separation from whole human blood by Tripathi et al. (2016)}

A microdevice exhibiting plasma separation from undiluted blood was developed by Tripathi et al. (2016). The microdevice was fabricated using conventional photolithography technique on a single layer of PDMS. It was seen that these microdevices almost achieved 100\% efficiency in separation on undiluted blood.

The microdevice has helped in replacing the conventional plasma separation technique. The separation is achieved at the micro scale. These separations were classified as passive, which relied on external forces for cell separation; or active, which involved inertial, bio-physical and geometrical effects. The device is simple in fabrication, offers clog free operations, economical and effective and is better for continuous flow operations.

\section{Single layer microfluidic device by Eluru et al. (2016)}

Eluru et al. (2016) studied single layer microfluidic device to realize hydrodynamic 3D flow focussing. The method involved a flow focussing procedure, that uses sheath fluid to enclose a sample fluid in a single layer of PDMS.

Configuration is made in such a way so as to manipulate the sample fluid with respect to sheath fluid to achieve a desired flow focussing. The 3D flow focussing is attained in two sequential steps and in distinct regions. Simulations were also carried out for characterization and determination of optimum set of design parameters. 


\section{Discussion and conclusion}

Substantial amount of microfluidics works has been done internationally in the fields of Medicine, Genetics, Chemical reaction, and also in Oil and Gas industry. The advent of microfluidics has helped tremendously in two basic ways. These are time and space. Many calculations are sped up due to experiments performed on a microscale which takes days if performed through conventional methods.

The other factor is space. Microfluidic experimental setups take very minimal space. The whole experiment is can be performed on a famous term, "Lab-on-a-Chip". The most important part of the setup is the microfluidic chip. It is here that different experimentation such as flow behaviour, patterns, interfacial interactions, wettability, relative permeability studies can be performed. The analysis is done through recorded images and videos and other image processing software.

All around the globe, microfluidics for EOR has be conducted to study various theories and many diagnoses have also been carried out. The micromodels are based on many raw materials. Among them the popular ones are the use of glass micromodels and PDMS micromodels. The space required to perform experiments is also less due to small size of micromodels and the apparatus setup. Apart from that it is convenient and experiments can be repeated multiple times without worry of core damage as its structure is modelled on glass or PDMS bases which can be reproduce and reused many a times. Many published materials have helped shed light into the advantages of microfluidics in oil and gas industries. Collaborations between industries, laboratories and universities have helped gain momentum for EOR interests on microfluidics.

The work which we intend to do is inspired from the principle of microfluidics. It is a micro version of larger scale conventional experiments such as core flooding. Other areas such as medicine, genetics, chemistry have applied microfluidics in India. Microfluidics for enhanced oil recovery is a novel idea in India. The aim is to work on micromodel chips having pore structures resembling that of various rock samples such as sandstone, and limestone. Different fluid flows will be carried inside these micromodels which will act as part of displacement mechanisms. One example is that of water driving out crude oil through creation of front.

Inside the micromodels, the flow patterns, formation of fingers, front location with respect to time will be studied for different combinations of fluids and well as pore structures. After analysis the behaviour of fluids inside these micromodels will help in prediction flow process in actual rock in the subsurface. The micromodelling will help in conducting experiments in lesser amount of time in comparison to experiments on conventional scale.

Acknowledgements We thank Enhanced Oil Recovery Lab, Department of Petroleum Technology for providing a base to study microfluidic application in Oil and Gas Industry. The microfluidics review work has been done under the UGC Sponsored Indo-US Twenty-First Century Knowledge Project, Project no. F.No. 194-1/2009 entitled "Foam assisted $\mathrm{CO}_{2}$ Flooding for the depleted reservoirs of Upper Assam Basin and Candidate Reservoirs in Louisiana". Under this project we will carry out our microfluidic works on Enhanced Oil Recovery in the Oil and Gas Industry.

Open Access This article is distributed under the terms of the Creative Commons Attribution 4.0 International License (http://creativeco mmons.org/licenses/by/4.0/), which permits unrestricted use, distribution, and reproduction in any medium, provided you give appropriate credit to the original author(s) and the source, provide a link to the Creative Commons license, and indicate if changes were made.

\section{References}

Al-Dhahli A, Geiger S, van Dijke M (2014) Impact of pore-scale threephase flow for arbitrary wettability on reservoir-scale oil recovery. J Pet Sci Eng 121:110-121. https://doi.org/10.1016/j.petro 1.2014.06.018

Bandyopadhyay D, Sharma A, Joo SW, Qian S (2010) Self-organized micropatterning of thin viscous bilayers under microgravity. Microgravity Sci Technol 22:273-282. https://doi.org/10.1007/ s12217-010-9188-7

Blunt MJ (2001) Flow in porous media-pore-network models and multiphase flow. Curr Opin Colloid Interface Sci 6:197-207. https ://doi.org/10.1016/S1359-0294(01)00084-X

Blunt M, Fayers FJ, Orr FM Jr (1993) Carbon dioxide in enhance oil recovery. Energy Convers Manag 34:1197-1204. https://doi. org/10.1016/0196-8904(93)90069-M

Buchgraber M (2008) An enhanced oil recovery micromodel study with associative and conventional polymers. University of Leoben, Leoben

Buchgraber M, Al-Dossary M, Rooss CM, Kovscek AR (2012) Creation of a dual-porosity micromodel for pore-level visualisation of multiphase flow. J Pet Sci Eng. https://doi.org/10.1016/j.petro 1.2012.03.012

Conn CA (2014) The characterization and visualisation of multi-phase systems using microfluidic devices. Rice University, Houston

Eluru G, Julius LAN, Gorthi SS (2016) Single-layer microfluidic device to realize hydrodynamic 3D flow focusing. Lab Chip. https ://doi.org/10.1039/C6LC00935B

Emami Meybodi H, Kharrat R, Wang X (2011) Study of microscopic and macroscopic displacement behaviours of polymer solution in water wet and oil-wet media. Transp Porous Med 89:97. https:// doi.org/10.1007/s11242-011-9754-5

Folles $\emptyset \mathrm{HN}$ (2012) Fluid displacements during multiphase flow visualised at the pore scale using micromodels. University of Bergen, Bergen

Gogoi SB (2011) Adsorption-desorption of surfactant for enhance oil recovery. Transp Porous Med 90:589-604. https://doi. org/10.1007/s11242-011-9805-y

Gogoi SB (2013) Carbon-dioxide for EOR in Upper Assam basin. In: Hou M, Xie H, Were P (eds) Clean energy systems in the subsurface: production, storage and conversion. Springer series in geomechanics and geoengineering. Springer, Berlin, pp 157-169 
Jung J, Jang J, Ahn J (2016) Characterization of a polyacrylamide solution used for remediation of petroleum contaminated soils. Materials. https://doi.org/10.3390/ma9010016

Kamari E, Rashtchian D, Shadizadeh S (2011) Micro-model experimental study of fracture geometrical effect on breakthrough time in miscible displacement process. Iran J Chem Chem Eng 30:1-7

Karadimitriou NK, Hassanizadeh SM (2012) A review of micromodels and their use in two-phase flow studies. Vadose Zone J. https:// doi.org/10.2136/vzj2011.0072

Kenzhekhanov S (2017) Chemical EOR process visualisation using NOA81 micromodels. Colorado School of Mines, Golden

Lacey M, Hollis C, Oostrom M, Shokri N (2017) Effects of pore and grain size on water and polymer flooding in micromodels. Energy Fuels. https://doi.org/10.1021/acs.energyfuels.7b01254

Larpudomlert R, Torrealba VA, Karpyn ZT, Halleck P (2014) Experimental investigation of residual saturation in mixed-wet porous media using a pore-scale model approach. J Pet Explor Prod Technol 4:175-187. https://doi.org/10.1007/s13202-013-0076-8

Mattax CC, Kyte JR (1961) Ever see a water flood? Oil Gas J 59:115-128

Nath N, Arun RK, Chanda N (2014) A paper based microfluidic device for the detection of arsenic using a gold nanosensors. RSC Adv. https://doi.org/10.1039/C4RA12946F

Nguyen P (2016) Microfluidic and micro-core methods for enhanced oil recovery and carbon storage applications. University of Toronto, Toronto

Nilsson MA, Kulkarni R, Gerberich L, Hammond R, Singh R, Baumhoff E, Rothstein JP (2013) Effect of fluid rheology on enhanced oil recovery in a microfluidic sandstone device. J Nonnewton Fluid Mech 202:112-119. https://doi.org/10.1016/j.jnnfm .2013.09.011
Sarmah S, Gogoi SB, Barman J, Dutta D (2017) Study on the effects of the rheological properties for flow behaviour of Assam crude oil with various chemicals. In: Singh DN, Galaa A(eds) Contemporary issues in environmental engineering. Springer, Basel, pp 148-168

Schneider MH, Sieben VJ, Kharrat AM, Mostowfi F (2013) Measurement of asphaltenes using optical spectroscopy on a microfluidic platform. Anal Chem 85:5153-5160. https://doi.org/10.1021/ ac400495x

Soo H, Radke CJ (1984) The flow mechanism of dilute, stable emulsions in porous media. Ind Eng Chem Fundam 23:346-347

Soo H, Radke CJ (1986) A filtration model for the flow of dilute, stable emulsion in porous media-I. Theory. Chem Eng Sci 41:263-272

Tripathi S, BalaVarun Kumar YV, Agrawal A, Prabhakar A, Joshi SS (2016) Microdevice for plasma separation from whole human blood using bio-physical and geometrical effects. Sci Rep. https ://doi.org/10.1038/srep26749

Tsakiroglou C, Vizika-Kavvadias O, Lenormand R (2013) Use of micromodels to study multiphase flow in porous media. In: International symposium of the society of core analysts, Napa Valley, California, USA p 1/13

Whitesides GM (2006) The origins and the future if microfluidics. Nature. https://doi.org/10.1038/nature05058

Wouters B, Schoenmakers PJ, Eeltink S (2014) Design of a microfluidic chip for spatial three dimensional liquid chromatography separations. In: 18th International conference on miniaturized systems for chemistry and life sciences, San Antonio, Texas, USA, pp 2636-2638

Publisher's Note Springer Nature remains neutral with regard to jurisdictional claims in published maps and institutional affiliations. 